\title{
Pão caseiro com inclusão de diferentes níveis de aparas (corte em "v") de tilápia
}

\section{defumadas}

\author{
Homemade bread with inclusion of different levels of shavings (cut in " $v$ ") of smoked tilapia \\ Pan casero con inclusión de diferentes niveles de virutas (cortadas en "v") de tilapia ahumada
}

Recebido: 10/09/2021 | Revisado: 19/09/2021 | Aceito: 27/09/2021 | Publicado: 27/09/2021

\author{
Maria Luiza Rodrigues de Souza \\ ORCID: https://orcid.org/0000-0001-5643-0841 \\ Universidade Estadual de Maringá, Brasi \\ E-mail: mlrsouza@uem.br \\ Gislaine Gonçalves Oliveira \\ ORCID: https://orcid.org/0000-0002-7819-3493 \\ Universidade Estadual de Maringá, Brasil \\ E-mail: gislaine_oliveira14@hotmail.com \\ Sabrina Campos Sbaraini \\ ORCID: https://orcid.org/0000-0002-7165-6563 \\ Universidade Estadual de Maringá, Brasil \\ E-mail: sabrinacsbaraini@gmail.com \\ Sabrina Martins dos Santos \\ ORCID: https://orcid.org/0000-0002-6658-688X \\ Universidade Estadual de Maringá, Brasil \\ E-mail: sabrina.martins.dos.santos@hotmail.com \\ Marcos Antonio Matiucci \\ ORCID: https://orcid.org/0000-0003-2053-2672 \\ Universidade Estadual de Maringá, Brasil \\ E-mail:m.matiucci@hotmail.com \\ Ana Carolina Valente Junqueira de Castro \\ ORCID: https://orcid.org/0000-0001-8438-933X \\ Universidade Estadual de Maringá, Brasil \\ E-mail: caroldcastro586@gmail.com \\ Stefane Santos Corrêa \\ ORCID: https://orcid.org/0000-0001-6519-2400 \\ Universidade Estadual de Maringá, Brasil \\ E-mail: stefane.pescap@gmail.com \\ Fabricio Vieira dos Santos \\ ORCID: https://orcid.org/0000-0002-1242-8181 \\ Universidade Estadual de Maringá, Brasil \\ E-mail: fabriciovieiradsantos@gmail.com \\ Andresa Carla Feihrmann \\ ORCID: https://orcid.org/0000-0003-2389-0467 \\ Universidade Estadual de Maringá, Brasil \\ E-mail: andresafeihrmann@gmail.com \\ Edna Regina Netto de Oliveira \\ ORCID: https://orcid.org/0000-0003-4795-1498 \\ Universidade Estadual de Maringá, Brasil \\ e-mail: ernoliveira@uem.br \\ Elenice Souza dos Reis Goes \\ ORCID: https://orcid.org/0000-0003-2437-4800 \\ Universidade Federal da Grande Dourados, Brasil \\ E-mail: elenicegoes@ufgd.edu.br
}

\section{Resumo}

O presente trabalho teve como objetivo avaliar características físico-químicas, microbiológicas e sensoriais de pães caseiros com adição de aparas (corte em "V" do filé) de tilápia defumadas. As aparas foram submetidas ao processo de defumação com a adição de extrato de ervas aromáticas. Foram incluídos 0\%, 3\%, 6\% e 9\% de aparas defumadas em pães caseiros, sendo avaliados quanto à composição centesimal, microbiológica e sensorial. Todos os parâmetros avaliados na composição centesimal apresentaram diferença significativa $(\mathrm{P}<0,05)$. Foi observada uma equação quadrática para os teores de umidade, proteína bruta, lipídeos e valor calórico, através da qual pães com 3\% de inclusão de farinha de peixe apresentaram menores médias de umidade e proteína, porém maior média de lipídeos e valor calórico. Pães com 9\% de inclusão de farinha de peixe tiveram maior teor de proteína e menor de lipídeos. Foi observado 
um aumento linear do teor de cinzas, conforme acréscimo dos níveis de farinha de peixe. A análise microbiológica demonstrou que todos os pães caseiros estavam dentro dos padrões exigidos pela legislação, portanto aptos para serem consumidos. A análise sensorial indicou uma boa aceitação do produto pelos provadores, demostrando a viabilidade da inclusão de até $6 \%$ de farinha de aparas defumadas de peixe sem prejuízo para as propriedades organolépticas. Portanto, conclui-se que a inclusão de $6 \%$ de farinha de aparas defumadas de tilápia do Nilo é viável para aumentar o valor nutritivo de pães caseiros, tendo este produto ótima aceitação sensorial.

Palavras-chave: Composição química; Desenvolvimento de produto; Oreochromis niloticus.

\begin{abstract}
This study aimed to evaluate the physicochemical, microbiological and sensory characteristics of homemade breads with the addition of smoked tilapia shavings (cut in "V" fillet). The shavings were subjected to a smoking process with the addition of aromatic herb extract. $0 \%, 3 \%, 6 \%$ and $9 \%$ of smoked chips in homemade bread were included, being evaluated for proximate, microbiological and sensory composition. All parameters evaluated in the proximate composition showed a significant difference $(\mathrm{P}<0.05)$. A quadratic equation for moisture, crude protein, lipids and caloric content was observed, where breads with 3\% inclusion of fish meal had lower moisture and protein averages, but higher lipid and caloric value averages. Breads with $9 \%$ fishmeal inclusion had higher protein content and lower lipid content. A linear increase in ash content was observed, as fish meal levels increased. Microbiological analysis showed that all homemade breads were within the standards required by legislation, therefore suitable for consumption. The sensory analysis indicated a good acceptance of the product by the tasters, demonstrating the viability of using up to $6 \%$ of smoked fish trimming flour inclusion without harming the organoleptic properties. Therefore, it is concluded that the inclusion of $6 \%$ of Nile tilapia smoked shavings flour is viable to increase the nutritional value of homemade breads, with this product having excellent sensory acceptance.
\end{abstract}

Keywords: Chemical composition; Oreochromis niloticus; Product development.

\title{
Resumen
}

Este estudio tuvo como objetivo evaluar las características fisicoquímicas, microbiológicas y sensoriales de los panes caseros con la adición de virutas de tilapia ahumada (cortada en filete en "V"). Las virutas se sometieron a un proceso de ahumado con la adición de extracto de hierbas aromáticas. Se incluyeron 0\%, 3\%, 6\% y 9\% de chips ahumados en pan casero, siendo evaluados por composición proximal, microbiológica y sensorial. Todos los parámetros evaluados en la composición próxima mostraron una diferencia significativa $(\mathrm{P}<0.05)$. Se observó una ecuación cuadrática de humedad, proteína cruda, lípidos y contenido calórico, donde los panes con 3\% de inclusión de harina de pescado tenían promedios de humedad y proteína más bajos, pero promedios de valor calórico y de lípidos más altos. Los panes con un $9 \%$ de inclusión de harina de pescado tenían un mayor contenido de proteínas y un menor contenido de lípidos. Se observó un aumento lineal en el contenido de cenizas a medida que aumentaban los niveles de harina de pescado. El análisis microbiológico mostró que todos los panes caseros se encontraban dentro de los estándares exigidos por la legislación, por lo que eran aptos para el consumo. El análisis sensorial indicó una buena aceptación del producto por parte de los catadores, demostrando la viabilidad de utilizar hasta un 6\% de inclusión de harina de corte de pescado ahumado sin perjudicar las propiedades organolépticas. Por tanto, se concluye que la inclusión de un $6 \%$ de harina de virutas ahumadas de tilapia del Nilo es viable para incrementar el valor nutricional de los panes caseros, teniendo este producto una excelente aceptación sensorial.

Palabras clave: Composición química; Desarrollo de producto; Oreochromis niloticus.

\section{Introdução}

No Brasil, o pão é um produto muito popular devido a aspectos culturais, características sensoriais e fácil disponibilidade, sendo consumido com outros alimentos e em várias refeições. Com isso, a busca por alimentos mais nutritivos tem aumentado com o passar dos anos, e a preocupação com o meio ambiente também (Azevedo et al., 2011). Nesse sentido, diversos estudos têm sido realizados nos últimos anos, buscando aumentar o valor nutritivo de produtos alimentícios através da utilização de subprodutos da indústria de beneficiamento do pescado.

A utilização de produtos oriundos de resíduos da indústria pesqueira pode ser uma excelente alternativa para o enriquecimento nutricional de produtos para consumo humano, pois os pescados são uma fonte rica em nutrientes, vitaminas, minerais, selênio, fósforo e cálcio, proteína e aminoácidos, que são essenciais para a saúde (Tilami \& Sampels, 2018).

O crescente aumento da produção aquícola brasileira é enfatizado pelo cultivo de tilápia do Nilo (Oreochromis niloticus), que alcançou a marca de 486.155 toneladas em 2020 (Peixe-Br, 2021). O processamento do pescado gera uma alta quantidade de resíduos, visto que o rendimento do filé representa cerca de 40\%, em função de características morfológicas e 
método de filetagem (Barroso et al., 2017). Assim, esses resíduos podem ser utilizados na preparação de outros alimentos, por possuir excelentes características nutricionais (Matiucci et al., 2020a), gerando uma diminuição dos impactos ambientais causados pelo descarte inadequado destes resíduos.

Vários produtos já foram desenvolvidos utilizando essa tecnologia, como toucinho em kaftas elaboradas com aparas de filés de tilápia (Souza et al., 2021a), alfajor (Kimura et al., 2017), pizza (Verdi et al., 2020) barra de cereal (Matiucci et al., 2020b), entre outros.

Ao melhorar o valor nutricional do pão, importante fonte energética e produto acessível a todas as classes sociais, espera-se contribuir para o aumento da qualidade da dieta da população, particularmente, crianças de baixa renda, assim como proporcionar um maior consumo de peixes, mesmo que indiretamente pela população especialmente que não gosta de consumir peixe.

O objetivo deste trabalho foi desenvolver um pão caseiro com adição de aparas (corte em "V" do filé) de tilápia defumadas, avaliando suas características físico-químicas, microbiológicas e sensoriais.

\section{Metodologia}

\section{Elaboração da farinha de aparas defumadas de tilápia do Nilo}

Com o processo de filetagem, são retiradas as aparas através de um corte em "V" dos filés, processo que remove as espinhas intramusculares da região próxima à linha lateral. As aparas utilizadas neste estudo foram obtidas de um frigorífico de peixes localizado em Rolândia, Paraná (SmartFish). Os demais ingredientes foram adquiridos no comércio local.

As aparas de filetagem foram lavadas e imersas em uma solução de salmoura a 20\%, na proporção de 2:1 (volume da salmoura/peso), 30 minutos. Nessa salmoura também foi adicionado extrato de alecrim, na proporção de 1:25 (extrato de alecrim: salmoura). Decorrido esse período as aparas foram colocadas em bandejas teladas para serem drenadas (60 minutos), para redução da água superficial. Em seguida, as aparas foram submetidas à defumação a quente, sendo colocadas dentro da câmara de defumação, para secagem parcial (aquecido a gás) a uma temperatura de $50^{\circ} \mathrm{C}$, por 60 minutos. Decorrido esse período, foi adicionada fumaça por 3 horas e controlada a temperatura dentro da câmara de defumação, durante todo o processamento, para iniciar a $60^{\circ} \mathrm{C}$ e depois acrescentar $10^{\circ} \mathrm{C}$ por hora de processo, até atingir $80^{\circ} \mathrm{C}$. O combustível utilizado para produzir a fumaça foi serragem de eucalipto rosa (Eucalyptus globulus Labill) e, para manutenção da temperatura, o gás de cozinha. A fumaça foi gerada fora da câmara de defumação.

Após defumação das aparas, estas foram desidratadas por 24 horas a $60^{\circ} \mathrm{C}$. Após, as aparas foram moídas e embaladas em saco plástico, a vácuo e mantidas congeladas até a confecção dos pães.

\section{Formulação e preparo dos pães caseiros enriquecidos com aparas de tilápia defumadas}

Este estudo pode ser caracterizado como experimental (Pereira et al., 2018). Foram desenvolvidos pães com inclusão de $0,3,6$ e $9 \%$ de farinha de aparas defumadas de tilápia do Nilo, utilizando as formulações apresentadas na Tabela 1. 
Tabela 1. Formulações dos pães com inclusão de farinha de aparas defumadas de tilápia do Nilo.

\begin{tabular}{lcccc} 
& & & Níveis de inclusão de farinha de aparas defumadas $^{1}$ \\
\cline { 2 - 5 } Ingredientes $(\mathrm{g})$ & $0 \%$ & $3 \%$ & $6 \%$ & $9 \%$ \\
\hline Farinha de trigo $^{2}$ & 1000 & 970 & 940 & 910 \\
Farinha de aparas defumadas de tilápia & 0 & 30 & 60 & 90 \\
Água & 250 & 250 & 120 & 250 \\
Óleo de soja & 120 & 115 & 115 & 120 \\
Açúcar & 115 & 27,5 & 27,5 & 115 \\
Sal & 27,5 & 10 & 10 & 27,5 \\
Fermento biológico seco & 10 & 10 & \\
\hline
\end{tabular}

${ }^{1}$ Inclusão com base no total de farinha de trigo. ${ }^{2}$ Teor de proteínas: $10 \mathrm{~g} / 100 \mathrm{~g}$. Fonte: Autores (2021).

Para produção dos pães, os ingredientes foram colocados em recipiente de plástico e a massa foi sovada até completa homogeneização e boa consistência. A massa pronta foi deixada descansar por 2 horas. Após foi dividida em cinco porções para abertura da massa e para enrolar os pães, que foram então colocados em formas e ficaram em descanso por mais duas horas. Os pães foram assados em forno quente $280{ }^{\circ} \mathrm{C}$ durante 40 minutos. Depois de frios, foram retiradas as amostras dos pães para as análises. Para as análises microbiológicas e sensorial foram embaladas em saco plásticos e colocadas em refrigerador $\left( \pm 5^{\circ} \mathrm{C}\right)$. Para as físico-químicas foram congeladas $\left(-18^{\circ} \mathrm{C}\right)$.

\section{Análise de composição centesimal e valor calórico}

Foram realizadas análises de composição centesimal, sendo que os teores de umidade, cinzas, lipídeos totais e proteínas foram determinados conforme metodologia do Instituto Adolfo Lutz (1985). Os carboidratos totais foram calculados pela diferença do somatório dos percentuais dos compostos analisados por $100 \%$. O valor calórico foi calculado para $100 \mathrm{~g}$ de amostra e para uma porção do produto, conforme proposto pela Anvisa/MS (2005).

As análises foram realizadas em triplicata a partir de uma amostra composta pela homogeneização de 5 pães aleatoriamente selecionados.

\section{Análise microbiológica}

As análises microbiológicas foram realizadas para o número mais provável (NMP) de coliformes a $35^{\circ} \mathrm{C} / \mathrm{grama}$ e 45 ${ }^{\circ} \mathrm{C} /$ grama, contagem de Estafilococos coagulase positiva em unidade formadora de colônia (UFC)/grama e de presença de Salmonella spp em 25 g, de acordo com APHA (1992).

\section{Análise sensorial}

$\mathrm{Na}$ análise sensorial, foram avaliando os atributos de aroma, cor do miolo, sabor, textura e impressão global, utilizando escala hedônica de 9 pontos (1- desgostei muitíssimo e 9- gostei muitíssimo) de acordo Dutcosky (2011). A intenção de compra foi avaliada utilizando uma escala hedônica ancorada entre 1 (certamente não compraria) e 5 (certamente compraria). A análise foi realizada em laboratório de análise sensorial, em cabines separadas, com 80 avaliadores não treinados, aleatoriamente selecionados e sem qualquer conhecimento sobre a composição das amostras. As amostras foram embaladas em papel alumínio, identificadas com três números diferentes e oferecidas aos provadores de maneira aleatória. Para realização da análise sensorial os provadores receberam todas as instruções para procederem a avaliação adequadamente. A análise sensorial foi avaliada e aprovada pelo Comitê de Ética da Universidade Estadual de Maringá (UEM), com Registro CAEE: 71048517.2.0000.0104. O 
estudo foi realizado conforme os preceitos da Resolução 196/96 do Conselho Nacional de Saúde.

\section{Análise estatística}

Foi aplicado um delineamento inteiramente casualizado nos dados obtidos nas diferentes análises e submetidos à análise de variância (ANOVA) a 5 \% de significância, sendo procedida análise de regressão, ou teste de Tukey, com auxílio do programa estatístico Statistical Analysis System (SAS Inst. Inc., Cary, NC, USA, 2010).

\section{Resultados e Discussão}

\section{Composição centesimal e valor calórico}

Os pães caseiros com inclusão de aparas defumadas trituradas de peixe apresentaram diferença significativa para todos os parâmetros avaliados (Tabela 2). Os pães com 3\% de inclusão de farinha de peixe apresentaram menor teor de umidade. Pode ser observada a equação $y=0,269 x 2-2,795 x+28,14\left(R^{2}=0,871\right)$ (Figura 1 A), demonstrando efeito quadrático para esse parâmetro. Isto também pode estar associado à distribuição dos pães dentro do forno e a dificuldade de todos os pães dos diferentes tratamentos serem assados simultaneamente. A redução dos teores de umidade pode estar relacionada à umidade da farinha de trigo, que, sendo em torno de $13 \%$ (Gutkoski et al., 2011), era superior à umidade da farinha de aparas de tilápia, que é de 8,89\% (Souza et al., 2021b).

Tabela 2. Composição centesimal de pães com diferentes níveis de inclusão de farinha de aparas defumada.

\begin{tabular}{|c|c|c|c|c|c|c|}
\hline $\begin{array}{l}\text { Níveis } \\
(\%)\end{array}$ & $\begin{array}{c}\text { Umidade } \\
(\%)\end{array}$ & $\begin{array}{c}\text { Proteína bruta } \\
(\%)\end{array}$ & $\begin{array}{c}\text { Lipídeos } \\
(\%)\end{array}$ & $\begin{array}{c}\text { Cinzas } \\
(\%)\end{array}$ & $\begin{array}{c}\text { Carboidratos } \\
(\%)\end{array}$ & $\begin{array}{c}\text { Valor calórico } \\
\text { (kcal/100 g) }\end{array}$ \\
\hline 0 & $28,61 \pm 4,55$ & $7,07 \pm 0,248$ & $7,90 \pm 0,42$ & $1,69 \pm 1,76$ & $54,74 \pm 2,61^{\mathrm{b}}$ & $264,11 \pm 8,89^{b}$ \\
\hline 3 & $20,78 \pm 3,28$ & $4,63 \pm 2,192$ & $8,71 \pm 0,39$ & $3,18 \pm 0,27$ & $62,71 \pm 5,36^{\mathrm{a}}$ & $287,05 \pm 14,05^{a}$ \\
\hline 6 & $22,48 \pm 1,58$ & $6,89 \pm 0,067$ & $8,46 \pm 0,14$ & $4,01 \pm 0,56$ & $58,16 \pm 0,81^{\mathrm{b}}$ & $277,65 \pm 4,64^{\mathrm{ab}}$ \\
\hline 9 & $24,36 \pm 0,31$ & $8,70 \pm 0,250$ & $8,22 \pm 0,09$ & $4,93 \pm 1,48$ & $53,79 \pm 3,56^{\mathrm{b}}$ & $267,18 \pm 5,83^{\mathrm{b}}$ \\
\hline Valor de $\mathrm{P}$ & $0,012^{1}$ & $0,003^{1}$ & $0,006^{1}$ & $<0,001^{1}$ & $<0,001^{2}$ & $0,004^{2}$ \\
\hline $\begin{array}{l}\text { Coeficiente de } \\
\text { Variação (\%) }\end{array}$ & 6,31 & 9,08 & 2,43 & 5,64 & 2,65 & 2,46 \\
\hline
\end{tabular}

Médias \pm desvio padrão. ${ }^{1}$ Equações de regressão apresentadas na Figura $1 .{ }^{2}$ Médias seguidas de letras diferentes na mesma coluna diferem pelo teste de Tukey a 5\% de probabilidade. Fonte: Autores (2021). 
Figura 1. Equação obtida através da análise de regressão. A) equação quadrática para umidade; B) equação quadrática para proteína bruta; C) equação linear para lipídeos; D) equação quadrática para cinzas.

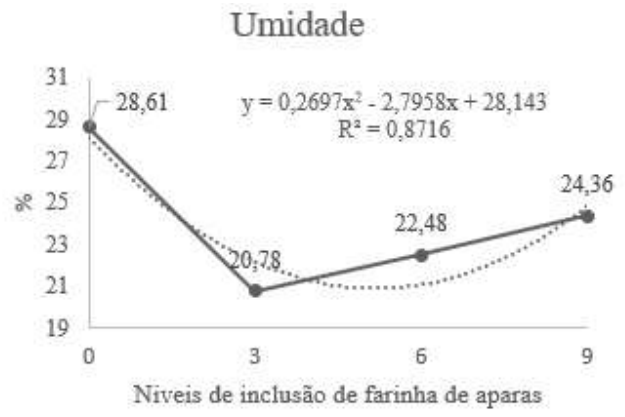

Lipídeos

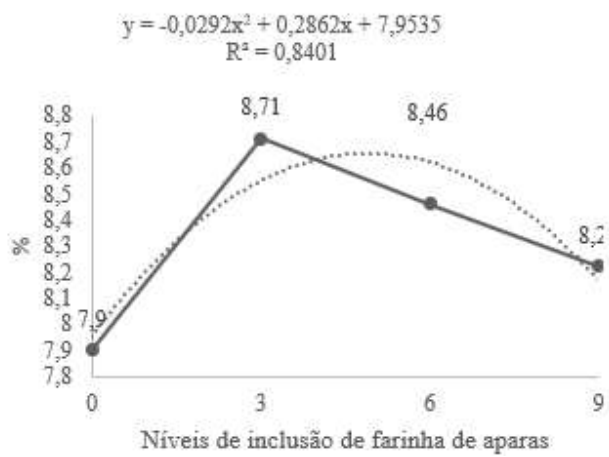

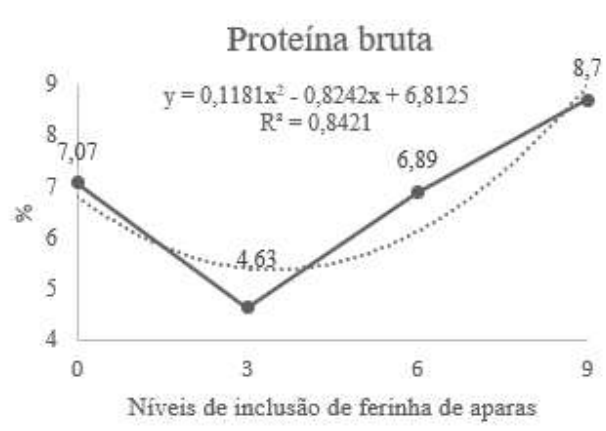

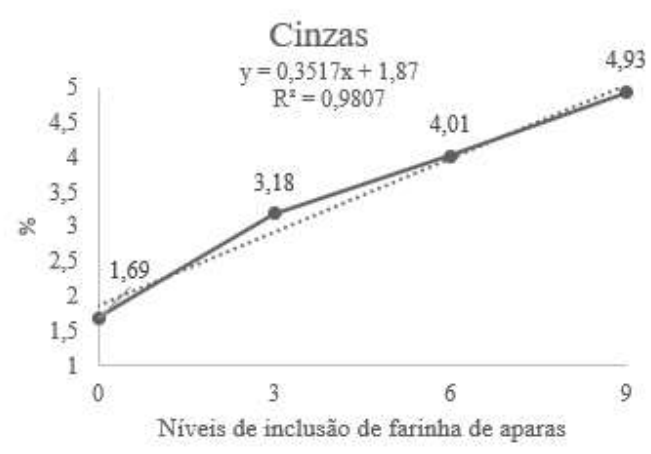

Fonte: Autores (2021).

Houve efeito quadrático para proteína bruta, sendo que para 3\% de inclusão da farinha de aparas defumada apresentou o menor teor de proteína bruta. A equação observada é y =0,118x2 - 0,824x $+6,812\left(\mathrm{R}^{2}=0,84\right)$ (Figura 1B). Os teores de lipídeos, carboidratos e valor calórico apresentaram efeito quadrático, sendo o maior teor para 3\% de inclusão de farinha de aparas defumada de peixe. Para lipídeos observa-se a Figura $1 \mathrm{C}$, cuja equação é y = -0,029x2 +0,286x +7,953 ( $\left.\mathrm{R}^{2}=0,84\right)$. As cinzas apresentaram efeito linear (Figura 1D), cuja equação é y $=0,351 x+1,87\left(R^{2}=0,98\right)$, demonstrando que conforme o aumento da inclusão de farinha de aparas, houve um acréscimo nos teores de cinzas.

Portanto, pode-se observar que o acréscimo no teor de proteína aconteceu somente com a inclusão de $9 \%$ de farinha de aparas. Possivelmente, esta farinha de aparas possuía teores de lipídeos e de cinzas bastante expressivos, o que resultou em níveis maiores destes nutrientes, em detrimento do teor de proteína bruta. Trabalho anterior demonstrou que a farinha de aparas defumadas de tilápia do Nilo possui 11,68 \% de lipídeos, 15,97 \% de cinzas e 60,87 \% de proteínas (Souza et al., 2021b).

Resultados diferentes foram obtidos em estudo avaliando a inclusão de farinha de carcaça de tilápia do Nilo em pão francês, onde foi observado aumento linear no teor de proteína e diminuição linear dos teores de umidade e carboidratos, conforme inclusão de 0, 5, 10 e $15 \%$ de farinha de carcaças de tilápia (Chambó et al., 2018). Também, em pães com adição de polpa do peixe cabrinha foi observado o aumento dos teores de proteína (Centenaro et al., 2007).

O aumento no teor de cinzas dos pães (de 1,69 a 4,93\% para 0 a 9\% de inclusão de farinha de peixe, respectivamente) pode ser considerado benéfico, visto que a carne de pescado é fonte principalmente de cálcio e de fósforo (Sartori e Amancio, 2012), minerais importantes para a estrutura óssea.

\section{Análise microbiológica}

Os resultados obtidos na análise microbiológica dos pães com inclusão de farinha de aparas defumada de tilápia 
indicaram baixo número de coliformes a $35^{\circ} \mathrm{C}$ e a $45^{\circ} \mathrm{C}$, Estafilococos coagulase positiva e ausência de Salmonella spp (Tabela 3), mostrando que os pães estavam aptos à alimentação humana, estando dentro dos padrões microbiológicos exigidos pela legislação (Brasil, 2019). Resultados similares foram obtidos em pão francês com adição de farinha de carcaças de tilápia do Nilo (Chambó et al., 2018).

Tabela 3. Análise microbiológica de pães caseiros com diferentes níveis de inclusão de farinha de aparas defumada de tilápia do Nilo.

\begin{tabular}{|c|c|c|c|c|}
\hline $\begin{array}{l}\text { Nívei } \\
\text { s }(\%)\end{array}$ & $\begin{array}{l}\text { Coliformes a } 35^{\circ} \mathrm{C} \\
(\mathrm{NMP} / \mathrm{g})\end{array}$ & $\begin{array}{l}\text { Coliformes a } 45^{\circ} \mathrm{C} \\
(\mathrm{NMP} / \mathrm{g})\end{array}$ & $\begin{array}{l}\text { Estafilococos } \\
\text { coagulase positiva } \\
\text { (UFC/g) }\end{array}$ & Salmonella ssp em $25 \mathrm{~g}$ \\
\hline 0 & $<3$ & $<3$ & $<1 \times 10^{2}$ & Ausente \\
\hline 3 & $<3$ & $<3$ & $<1 \times 10^{2}$ & Ausente \\
\hline 6 & $<3$ & $<3$ & $<1 \times 10^{2}$ & Ausente \\
\hline 9 & $<3$ & $<3$ & $<1 \times 10^{2}$ & Ausente \\
\hline
\end{tabular}

NMP (Número Mais Provável); UFC (Unidades Formadoras de Colônias). Fonte: Autores (2021).

\section{Análise sensorial}

Os resultados obtidos na análise sensorial dos pães caseiros com inclusão de farinha de aparas defumadas podem ser observados na Tabela 4. Foram verificadas diferenças $(\mathrm{P}<0,05)$ em todos os atributos analisados, exceto para o aroma dos pães, cujas notas variaram de 6,93 a 7,72. As equações de regressão para os atributos com resultado significativo podem ser observadas na Figura 2. Pode-se verificar que com o aumento dos níveis de inclusão, há uma diminuição da aceitabilidade dos pães, onde parâmetros como textura, sabor e intenção de compra foram inferiores para pães com 9 \% de inclusão de farinha de aparas defumadas de tilápia do Nilo.

Tabela 4. Análise sensorial de pães com diferentes níveis de inclusão de farinha de aparas defumadas de tilápia do Nilo.

\begin{tabular}{llllllc}
\hline \multirow{2}{*}{ Variáveis } & \multicolumn{3}{c}{ Níveis (\%) } & \multicolumn{2}{c}{$\begin{array}{c}\text { Coeficiente } \\
\text { de Variação } \\
(\%)\end{array}$} \\
\cline { 2 - 5 } Cor & 0 & 3 & 6 & 9 & \multicolumn{2}{c}{ Valor de P } \\
Aroma & $8,02 \pm 1,07$ & $6,88 \pm 0,07$ & $6,43 \pm 0,52$ & $6,47 \pm 0,48$ & $<0,001^{1}$ & 22,75 \\
Textura & $7,72 \pm 0,52$ & $7,16 \pm 0,04$ & $6,98 \pm 0,22$ & $6,93 \pm 0,27$ & 0,05 & 23,88 \\
Sabor & $8,14 \pm 1,12$ & $6,72 \pm 0,30$ & $6,78 \pm 0,24$ & $6,45 \pm 0,57$ & $<0,001^{1}$ & 21,28 \\
\hline Impressão global & $8,10 \pm 1,18$ & $7,16 \pm 0,24$ & $6,41 \pm 0,51$ & $6,00 \pm 0,92$ & $<0,001^{1}$ & 26,49 \\
Intenção de compra & $8,12 \pm 1,15$ & $6,97 \pm 0,00$ & $6,43 \pm 0,54$ & $6,38 \pm 0,59$ & $<0,001^{1}$ & 23,66 \\
\hline
\end{tabular}

Médias \pm desvio padrão. ${ }^{1}$ Equações de regressão apresentadas na Figura 2. Fonte: Autores (2021). 
Figura 2. Representação gráfica dos atributos sensoriais de pão caseiro com inclusão de diferentes níveis de farinha elaboradas a partir de aparas defumada de tilápia e equações de regressão referente a cada atributo analisado.
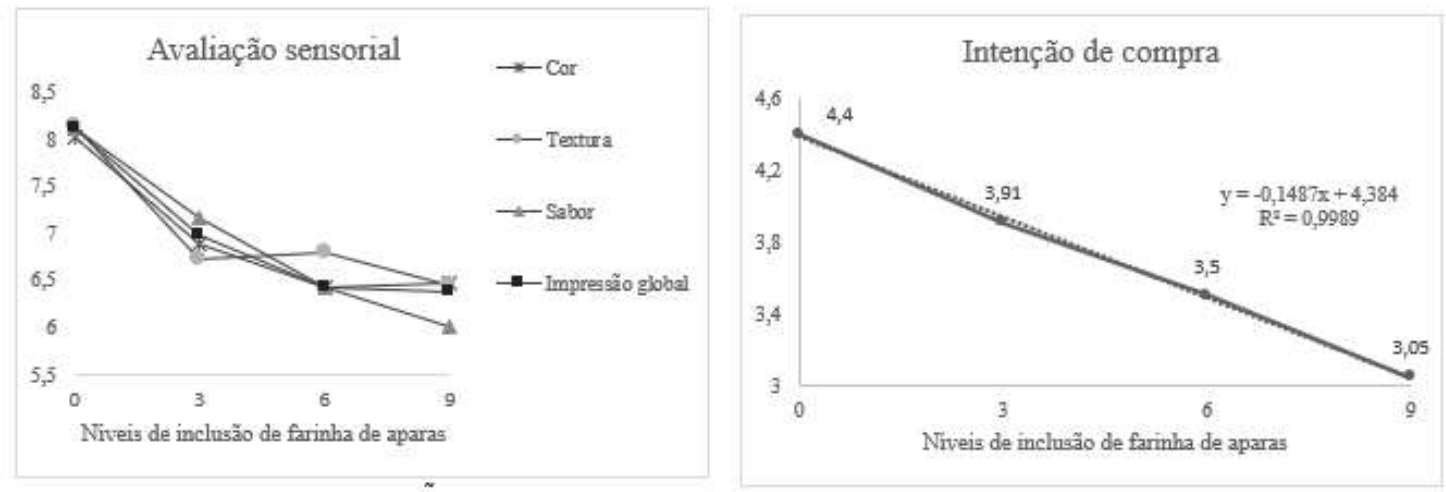

Equações de regressão

\begin{tabular}{lll}
\hline Cor & $\mathrm{y}=0,295 \mathrm{x}^{2}-1,985 \mathrm{x}+9,700$ & $\mathrm{R}^{2}=0,9988$ \\
\hline Textura & $\mathrm{y}=-0,3117 \mathrm{x}^{3}+2,61 \mathrm{x}^{2}-7,0683 \mathrm{x}+12,91$ & $\mathrm{R}^{2}=0.9988$ \\
\hline Sabor & $\mathrm{y}=-0,705 \mathrm{x}+8,68$ & $\mathrm{R}^{2}=0.9721$ \\
\hline Impressão global & $\mathrm{y}=0,275 \mathrm{x}^{2}-1,951 \mathrm{x}+9,790$ & $\mathrm{R}^{2}=0,9996$ \\
\hline Intenção de compra & $\mathrm{y}=-0,1487 \mathrm{x}+4,384$ & $\mathrm{R}^{2}=0,9989$ \\
\hline
\end{tabular}

Fonte: Autores (2021).

Fukushima et al. (2014) avaliando a inclusão (0\% sendo o padrão, 5\%, 10\% 15\% e 20\%) da farinha do resíduo da filetagem de tilápia na fabricação de pães de forma, relataram que os pães com melhor sabor, textura e aspecto global foram o pão padrão, pão com 5\% de farinha de tilápia e o pão com 15\% de farinha de tilápia. Os autores explicam que o pão com 5\% de farinha de tilápia ficou semelhante ao pão padrão devido a baixa porcentagem de farinha de peixe, já o pão com $15 \%$ ficou semelhante ao pão integral e agradou os consumidores, se enquadrando entre as categorias "gostei ligeiramente" a gostei moderadamente", isto levando em consideração a escala hedônica de Stone e Sidel (1993) e Dutcosky (2011). Fukushima et al. (2014) apresentaram notas inferiores às obtidas neste experimento do pão caseiro com inclusão de aparas defumadas. Segundo os autores para os atributos sabor, textura e aspecto global, as notas para o pão padrão variaram de 6,72 a 6,74, para 5\% de inclusão de 6,20 a 6,33 e para $10 \%$ foi de 5,93 a 6,03. Para a intenção de compra, as notas reduziram $(3,57$ para 3,06) com o aumento da inclusão de até $10 \%$ de farinha de resíduo de filetagem de tilápia. Portanto, comparando estas notas relatadas pelos autores com os resultados obtidos neste experimento com a inclusão de aparas defumadas no pão caseiro (6\% e $9 \%)$ que são os valores mais próximo dos avaliados pelos autores (5 e 10\%), as notas deste experimento foram superiores aos relatados por Fukushima et al. (2014), sendo para 5\% de 6,41 a 6,78 e intenção de compra a nota foi 3,5. Já para inclusão de $9 \%$ variou entre os mesmos atributos mencionados pelos autores de 6,0 para 6,45 e intenção de compra de 4, enquanto o pão padrão neste experimento foram notas de 8,1 a 8,14 e para intenção de compra de 4,4.

Pessatti (2001) elaborou um concentrado proteico de peixe através de lavagens sucessivas com etanol e relatou que o aroma foi caracterizado como de frutos do mar. As médias para as variáveis sabor variaram entre 6,35 e 8,02 e, portanto, estiveram na faixa de "gostei ligeiramente" e "gostei muito". Neste experimento, também as notas ficaram entre 6,93 a 7,16, valores estes muito próximos aos relatados por Pessatti (2001) para hambúrgueres, apesar de serem produtos totalmente diferentes a inclusão de farinha de aparas defumadas não piorou a palatabilidade dos produtos elaborados (hambúrgueres e pães).

De forma geral, as notas obtidas na análise sensorial para todos os atributos e em todos os tratamentos, ficaram em sua maioria próximas de 7. Esses valores são considerados bons, pois, de acordo com a tabela de aceitabilidade de Moraes (1993), Stone e Sidel (1993) e Dutcosky (2011), estes resultados indicam que os avaliadores gostaram moderadamente dos produtos. 
Porém, considerando a diminuição da aceitabilidade no nível mais alto de inclusão, o mais indicado seria a inclusão de no máximo $6 \%$ de farinha de aparas defumada de peixe.

\section{Conclusão}

A inclusão de farinha de aparas defumadas de tilápia do Nilo em pão caseiro altera suas características nutricionais e sensoriais. Sua utilização foi bem aceita pelos consumidores e melhorou a composição nutricional do pão, aumentando os níveis de proteína, lipídeos e matéria mineral. Em função da análise sensorial, recomenda-se a adição de até 6\% de farinha de aparas defumadas de tilápia do Nilo em pães caseiros. A análise microbiológica mostrou que os pães elaborados estavam aptos à alimentação humana, estando dentro dos padrões exigidos pela legislação. Novos estudos, avaliando outras porcentagens de inclusão, e com análises mais abrangentes sobre a composição físico-química, tecnológica e de vida de prateleira são sugeridas para a caracterização completa deste produto.

\section{Referências}

American Public Health Association (APHA). (1992). Committe on Microbiologycal Methods for Foods. Compendiun of Methods for the Microbiologycal Examination of Foods. APHA. 129p

Azevedo, F. L. A. A., Silva, A. D. F., Maciel, J. F., Moreira, R. T., \& Farias, L. R. G. (2011). Avaliação sensorial de pão de forma elaborado com soro de leite em pó. Revista Brasileira de Produtos Agroindustriais, 13(1), 37-47. http://dx.doi.org/10.15871/1517-8595/rbpa.v13n1p37-47

Barroso, R. M., Pincinato, R. B. M., \& Munoz, A. E. P. (2017). O mercado da tilápia-2 trimestre de 2017 e Análise da estrutura do preço da tilápia no varejo. Embrapa Pesca Aquic. Newsletter, 1, 1-19.

Brasil. (2019). Ministério da Saúde. Agência Nacional de Vigilância Sanitária. Instrução normativa ${ }^{\circ} 60$, de 23 de dezembro de 2019 . Estabelece as listas de padrões microbiológicos para alimentos. https://www.in.gov.br/en/web/dou/-/instrucao-normativa-n-60-de-23-de-dezembro-de-2019-235332356

Centenaro, G. S., Feddern, V., Bonow, E. T., \& Salas-Mellado, M. (2007). Enriquecimento de pão com proteínas de pescado. Food Science and Technology, 27, 663-668. https://doi.org/10.1590/S0101-20612007000300036

Chambó, A. P. S., Souza, M. L. R. D., Oliveira, E. R. N., Mikcha, J. M. G., Marques, D. R., Maistrovicz, F. C., Visentainer, J.V. \& Goes, E. S. R. (2018). Roll enriched with Nile tilapia meal: sensory, nutritional, technological and microbiological characteristics. Food Science and Technology, 38, 726-732. https://doi.org/10.1590/1678-457X.15317

Dutcosky, S.D. (2011). Análise sensorial de alimentos. (3a ed.), Champagnat, p. 426.

Gutkoski, L. C., Durigon, A., Mazzutti, S., Cezare, K. D., \& Colla, L. M. (2011). Influência do tipo de farinha de trigo na elaboração de bolo tipo inglês. Brazilian Journal of Food Technology, 14, 275-282. https://doi.org/10.4260/BJFT2011140400033

Kimura, K. S., de Souza, M. L. R., Verdi, R., Coradini, M. F., Mikcha, J. M. G., \& dos Reis Goes, E. S. (2017). Nutritional, microbiological and sensorial characteristics of alfajor prepared with dehydrated mixture of salmon and tilapia. Acta Scientiarum. Technology,39(1), 111-117. https://doi.org/10.4025/actascitechnol.v39i1.29164

Lutz, A. (1985). Normas Analíticas do Instituto Adolfo Lutz. Métodos químicos e físicos para análise de alimentos, 2. (3a ed.).

Matiucci, M. A., Alemida, G. C.A., da Silva, J. M., de Cássia Spacki, K., Chambo, A. P. S., Araujo, E.S., ... \& Vieira, A. M. S. (2020a). Aproveitamento e valorização de resíduos na filetagem de tilápia. Editora Atena. 1-388. https://doi.org/10.22533/at.ed.5252004111

Matiucci, M. A., Chambo, A. P. S., Mikcha, J. M. G., \& Souza, M. L. R. (2020b). Savory cereal bars made with seed, fruit peel, and fish meal. Acta Veterinaria Brasilica, 14(4), 265-271. https://doi.org/10.21708/avb.2020.14.4.9425

Moraes, M. A. (1993). Métodos para avaliação sensorial dos alimentos. Unicamp.

Peixe-Br. (2021). Anuário Peixe Br da Piscicultura 2020. Associação Brasileira de Piscicultura, 1-136.

Pereira, S. A., Shitsuka, D. M., Parreira, F. J. \& Shitsuka, R. (2018). Metodologia da pesquisa científica. UFSM, NTE.

Pessatti, M. L., Pereira, K., Stori, F., \& Buschi, F. (2001). Aproveitamento dos subprodutos do pescado: meta 11. Itajaí: Universidade do Vale do Itajaí, Relatório final de ações prioritárias ao desenvolvimento da pesca e aqüicultura no sul do Brasil, convênio Ministério da Agricultura, Pecuária e Abastecimento-MAPA.

Sartori, A. G. O., \& Amancio, R. D. (2012). Pescado: importância nutricional e consumo no Brasil. Segurança alimentar e nutricional, 19(2), 83-93. https://doi.org/10.20396/san.v19i2.8634613

SAS Institute (Cary, USA). (2010). SAS/STAT User guide, version 6. (4a ed.), Cary. 1, 943p. 
Research, Society and Development, v. 10, n. 12, e495101220458, 2021 (CC BY 4.0) | ISSN 2525-3409 | DOI: http://dx.doi.org/10.33448/rsd-v10i12.20458

Souza, M. L. R., Souza, E. D., Matiucci, M. A., Feihrmann, A. C., Oliveira, G. G., Sbaraini, S. C., Santos, S. M., Santos, F. V., Goes, M. D., Goes, E. S. R. (2021a). Inclusão de toucinho em kaftas elaboradas com aparas de filés de tilápia: composição química, microbiológica e sensorial. Ciência e Tecnologia de Alimentos. Editora científica. 386-400.

Souza, M. L. R., Silva, D. D. S., Pereira, I. L., Rocha, L. M. P., Oliveira, G. G., Coradini, M. F., ... \& Goes, E. S.R. (2021b). Inclusion levels of flour made from smoked Nile tilapia trimmings in extruded corn snacks. Research, Society and Development, 10(8), e33410817243-e33410817243. https://doi.org/10.33448/rsdv10i8.17243

Stone, H., Sidel, J.L. (1993). Sensory Evaluation Practices, (2a ed.), Academic Press. 338p.

Tilami, S., \& Sampels, S. (2018). Nutritional value of fish: lipids, proteins, vitamins, and minerals. Reviews in Fisheries Science \& Aquaculture, 26 (2), $243-253$. https://doi.org/10.1080/23308249.2017.1399104

Verdi, R., Gasparino, E., Coradini, M. F., Chambo, A. P. S., Feihrmann, A. C., Goes, E. S. R., \& Souza, M. L. R. (2020). Inclusion of dehydrated mix of tilapia and salmon in pizzas. Food Science and Technology, 40(4), 794-799. https://doi.org/10.1590/fst.22019 